\title{
Análise da saúde ambiental em grupos sociais no município de Diamante D’Oeste (PR)
}

\author{
Eduardo Bortoli Mariano ${ }^{1}$ \\ Irene Carniatto ${ }^{2}$ \\ Gustavo Henrique dos Reis ${ }^{3}$ \\ Elio Jacob Junior ${ }^{4}$
}

\begin{abstract}
Resumo
O presente trabalho buscou identificar os grupos sociais existentes no município de Diamante D’Oeste, localizado na mesorregião geográfica do Oeste paranaense, microrregião do município de Toledo, avaliando-lhes os principais agravos à saúde, relacionando as causas aos problemas e aos conflitos ambientais emergentes. Na pesquisa, que foi uma realização do GPEEA BIO UNIOESTE - Grupo de Pesquisa e Estudos em Educação Ambiental da Universidade Estadual do Paraná - utilizou-se a metodologia de mapeamento social, descrita pelo Grupo de Pesquisa em Educação Ambiental, Cultura e Arte (GPEA) da Universidade Federal do Mato Grosso (UFMT), com o objetivo de dar visibilidade aos grupos sociais invisíveis.
\end{abstract}

Palavras-chave: Mapeamento ambiental. Sustentabilidade rural e urbana. Comunidades sustentáveis.

\begin{abstract}
The following study sought to identify social groups in the city of Diamond D'Oeste evaluating the access to health care, and if the service is suitable for their needs, reporting the main health problems for those groups lacing causes related to environmental problems and conflicts emerging. Located in the geographical middle region of west's Paraná, Toledo City's county, the research was a realization of GPEEA BIO UNIOESTE - Group for Research and Studies on Education in Environmental from the West Paraná State University. The social mapping was the methodology used, this methodology was described by the Research Group on Environmental Education, Culture and Art (GPEA) from Mato Grosso Federal University (UFMT), aiming to give visibility to the invisible social groups.
\end{abstract}

Keywords: Environmental mapping. Rural and urban sustainability. Sustainable communities.

\footnotetext{
${ }^{1}$ Biólogo licenciado pela Universidade Estadual do Oeste do Paraná (UNIOESTE). eduardobortolli01@gmail.com

2 Pesquisadora e Docente do Programa de Pós-Graduação em Desenvolvimento Rural Sustentável e Curso de Ciências Biológicas da Universidade Estadual do Oeste do Paraná (UNIOESTE). irenecarniatto@gmail.com

3 Acadêmico do Curso de Ciências Biológicas da Universidade Estadual do Oeste do Paraná (UNIOESTE).gustah_reis@hotmail.com

${ }^{4}$ Mestrando do Programa de Pós-Graduação em Desenvolvimento Rural Sustentável (UNIOESTE). elio_jacob@hotmail.com
} 


\section{Introdução}

Para uma sociedade sustentável, necessita-se que a saúde e o desenvolvimento estejam intimamente relacionados, sendo que uma população mundial em expansão, como a nossa, possui um desenvolvimento insuficiente ou inadequado, propiciando um aumento maior das desigualdades sociais e, consequentemente, da pobreza. Neste cenário, surgem sérios problemas para a saúde, que podem estar relacionados ao meio ambiente, tanto em países emergentes, em desenvolvimento, ou já desenvolvidos.

Isso é possível observar através de estudos na área, como os que avaliam a satisfação das necessidades de atendimento primário de saúde, especialmente nas zonas rurais e em grupos sociais que estão na invisibilidade, o controle de moléstias contagiosas, a proteção dos grupos vulneráveis e a inserção da saúde urbana (IPARDES, 2011).

Define-se saúde pública como a ciência e a arte de promover, proteger e recuperar a saúde, por meio da motivação da população e de medidas de alcance coletivo, como saneamento do meio abiótico, controle de infecções, educação em higiene pessoal, estrutura e manutenção de saúde, organizações de serviços médicos e de enfermagem, para diagnóstico precoce e pronto tratamento das doenças, sistemas socioculturais, ambientais e econômicos (engenharia, medicina, biologia, sociologia, direito e outros), conferindo ao homem prosperidade, bem-estar, qualidade de vida e garantia de sobrevivência saudável no futuro (BRASIL, 2003).

A relação entre sociedade e natureza leva a transformações territoriais e reorganização do espaço, conforme as necessidades das atividades que devem ser realizadas, como a agricultura, a exploração mineral, o transporte de mercadorias, a produção de energia, a fabricação de produtos ou construção de cidades, construções de barragens, entre outras. No entanto, estas atividades podem ser propícias à ocorrência de determinadas doenças (MINAYO; MIRANDAN, 2002).

A saúde ambiental, conforme definida por Buss (2000), considera os aspectos da saúde humana, incluindo a qualidade de vida, os quais são determinados por fatores físicos, químicos, biológicos, sociais e psicológicos no meio ambiente, além de valorizar, corrigir, controlar e prevenir/evitar certos fatores do meio ambiente que poderão prejudicar a saúde das gerações atuais e futuras. Assim, quando se refere às políticas públicas, a saúde ambiental é compreendida como "o campo de atuação da saúde pública que se ocupa das formas de vida, substâncias e condições em torno do ser humano, que podem exercer alguma influência sobre a sua saúde e o seu bem-estar" (BRASIL, 2003).

Podemos citar como um agravo à saúde aquele causado pela falta de abastecimento de água potável e pela falta de coleta segura de esgotos, poluição atmosférica e gestão inadequada de resíduos sólidos, limpeza pública e urbanização intensiva (GIODA; NETO, 2003).

Os indicadores relativos à saúde evidenciam um quadro epidemiológico ligado à desigualdade de acesso da população ao sistema de saúde pública. A morbimortalidade por doenças causadas por vetores e veiculação hídrica coexiste com as doenças causadas por fatores, como poluição ambiental, qualidade dos alimentos e estresse. 0 meio ambiente, segundo Dominguez (1998), representa um dos quatro determinantes do estado de saúde da população. Em pesquisa realizada nos Estados Unidos, a questão 
ambiental representou $19 \%$ do total dos determinantes de saúde, índice superior aos dos serviços de saúde, que corresponde a $11 \%$.

O homem vem degradando o meio ambiente há séculos, promovendo agravos à saúde, que ocorrem também em consequência dos desastres ecológicos, dos quais são exemplos evidentes, no Brasil, chuvas em excesso, em algumas regiões, secas e estiagens, em outras; desmoronamentos em encostas. Primeiro o homem deixa seu rastro, consequentemente, mais tarde, a natureza também deixa seu rastro de degradação (COSTA; CARBONE, 2004).

Os fatores sociais podem influenciar a ocupação do espaço e a ecologia dos animais e vetores, alterando o ambiente e favorecendo os surtos epidêmicos. Dentre os fatores relacionados com o meio ambiente, destacam-se as mudanças ecológicas, incluindo aquelas realizadas pelo desenvolvimento econômico e uso das terras e das águas, exemplificadas pelas mudanças ocorridas com a agricultura, represas, mudanças nos ecossistemas hídricos, desflorestamento, enchentes, secas, fome, mudanças climáticas, isolamento de grupos sociais, etc. As doenças ocasionadas por essas mudanças podem ser febre hemorrágica coreana, leishmaniose, arbovírus, encefalite, síndromes febris, dentre outras (MINAYO; MIRANDAN, 2002).

Conforme Heller (1997), as doenças podem ser classificadas pelo quesito ambiental, de acordo com a sua transmissão, pois a maioria das doenças transmitidas para o homem é causada por microrganismos, destacando-se os vírus, as bactérias, os protozoários e os helmintos. Esta classificação ambiental das infecções origina-se da compreensão dos mecanismos de transmissão, que se agrupam em quatro categorias, sendo a foco-oral relacionada à higiene, baseada na água e transmissão por vetor. Castro (1995) também afirma que, além das doenças de origem biológica, a água pode ser ainda veículo para inúmeras substâncias químicas, capazes de desencadear doenças ao indivíduo que a consumir durante um período prolongado ou em quantidades elevadas. Várias doenças também podem ser transmitidas quando não há coleta e disposição adequada de resíduos sólidos. Como fator indireto, os resíduos sólidos têm grande influência na transmissão de doenças, através de vetores que nele encontram alimento, abrigo e condições adequadas de proliferação.

Além disso, ressaltam-se outras alterações na saúde que podem ocorrer por acidentes, durante o manuseio dos resíduos sólidos, muitas vezes, por falta de proteção adequada e da queima e disposição inadequada dos resíduos sólidos no solo, criando problemas de poluição do ar, do solo e das águas subterrâneas e superficiais. O local de construção da moradia é de extrema importância, uma vez que a habitação influencia nas doenças transmitidas pelo ar, seja pela falta de espaço, ventilação, temperatura ou umidade do ar (CASTRO, 1995).

Para obter medidas profiláticas relativas às vias de transmissão, aspectos tecnológicos de saneamento básico normalmente são empregados, constituindo-se num conjunto de ações que incluem o controle sanitário da água, solo, fezes, resíduo sólidos, entre outros (CÂMARA, 2002).

A saúde é uma qualidade necessária para o ser humano, envolvendo várias dimensões, entre as quais a biológica, que corresponde às condições de reprodução da própria espécie com qualidade; a social, que diz respeito à capacidade de transformação 
coletiva em seus aspectos naturais, sociais e simbólicos; a psicológica é aquela da subjetividade, da afetividade e da percepção sobre o bem-estar; a racional repousa sobre a capacidade reflexiva do ser humano e diz respeito à conduta e à consciência, tendo em vista a mudança de condição da existência humana, e a ambiental, que adquire novos significados na ampliação do conceito de saúde, permitindo ao ser humano uma melhor adaptação ao meio em que ele vive (TAMBELLINI; CÂMARA, 2003).

$\mathrm{Na}$ atualidade, a perda de qualidade e o esgotamento de elementos da natureza que são essenciais à vida, como a água, o solo, o ar e a biodiversidade, tornam os problemas de saúde muito mais incertos, do ponto de vista de seus desdobramentos sociais, políticos, econômicos, culturais, psicológicos e ecológicos. A junção território, ambiente e desenvolvimento formam uma conexão que deve ser contemplada pela saúde pública, para que se considere todo o conjunto de componentes materiais, paisagens e seres vivos em profunda relação (TAMBELLINI; CÂMARA, 2003).

O conceito saúde ambiental não se limita apenas a fatores sólidos, líquidos ou gasosos, mas a um todo, incluindo o mundo físico, junto com a população e suas relações. A saúde ambiental une-se à saúde coletiva pelas suas atividades de produção, saúde e ambiente. As relações de saúde e ambiente podem ser caracterizadas como relações de risco (LAZZAROTTO et al., 2007).

De acordo com Silva (2011), ressalta-se a importância de identificar e conhecer os grupos sociais muitas vezes excluídos, e, assim, esquecidos pelo poder público. Caracterizá-los é fundamental para que se possa exigir do poder público o seu devido reconhecimento como cidadãos brasileiros e também descobrir suas verdadeiras problemáticas.

Nesse sentido, o presente trabalho buscou identificar os grupos sociais no município, avaliando-Ihe o acesso à saúde e se o atendimento é adequado às suas necessidades, relatando os principais agravos à saúde para estes grupos, enlaçando as causas relacionadas aos problemas e conflitos ambientais emergentes.

\section{Metodologia}

A pesquisa foi desenvolvida com os diversos grupos sociais do município de Diamante D'Oeste, localizado na mesorregião geográfica do Oeste paranaense, microrregião do município de Toledo, sendo uma realização do GPEEA BIO UNIOESTE - Grupo de Pesquisa e Estudos em Educação Ambiental da Universidade Estadual do Paraná - Cascavel, na qual aproximadamente vinte participantes contribuíram no levantamento dos dados em campo e no mapeamento dos grupos sociais desse município pertencente à Bacia Hidrográfica do Paraná 3.

Utilizou-se a metodologia de mapeamento social, descrita pelo Grupo de Pesquisa em Educação Ambiental, Cultura e Arte (GPEA) da Universidade Federal do Mato Grosso (UFMT), com o objetivo de dar visibilidade aos grupos sociais invisíveis. Esta metodologia apresenta uma investigação narrativa dos representantes de vários grupos sociais, diagnosticando esses diferentes grupos, identidades e significados coletivos (CARNIATTO, 2007; SILVA, 2011). Foi desenvolvida uma pesquisa-ação, que teve o objetivo de buscar o conhecimento e a compreensão como parte da prática, unindo o sujeito e o objeto, podendo ser aplicada em qualquer ambiente de interação social que se caracterize por um 
problema no qual estão envolvidos pessoas, tarefas e procedimentos (BARBIER, 2002).

Amaral e Carniatto (2011) destacam que o aspecto marcante para este tipo de investigação é o de que o pesquisador pode intervir na realidade, auxiliando na solução dos problemas, no decorrer do processo, sendo a pesquisa feita num espaço que apresenta a totalidade que se pretende abranger.

Para o levantamento das informações sobre a situação da saúde ambiental dos diversos grupos sociais, foi realizada uma entrevista semiestruturada de forma mista, ou seja, abrangendo respostas abertas e objetivas, que podem ser previamente estabelecidas (sim, não, talvez), assim como respostas descritas pelos sujeitos (GIL, 2002).

A entrevista semiestruturada se desenrola a partir de um esquema básico, porém não aplicado rigidamente, permitindo que o entrevistador faça as necessárias adaptações. Esta é uma tática reflexiva, permitindo maior liberdade para entrevistador e entrevistado (LUDKE; ANDRÉ, 1986).

Em seguida, os dados foram analisados de forma qualitativa, o que enfatiza o processo, e não apenas o resultado final, além de permitir a compreensão do significado do fenômeno em seus contextos. Ela trabalha universalmente os significados, motivos, aspirações, crenças, valores e atitudes, assim aprofundando as relações dos processos e dos fenômenos que não podem ser reduzidos à operacionalização de variáveis (CARNIATTO, 2002).

Por outro lado, a pesquisa quantitativa se fundamenta nas ciências da natureza, que conduz seus conhecimentos por processos quantificáveis que se transformam, por técnicas de mensuração, em leis e explicações gerais (CHIZZOTTI, 1991).

Os dados foram submetidos à avaliação qualitativa, segundo os pressupostos teóricos de Flick (2004), cuja pesquisa baseia-se em várias abordagens teóricas das diferentes linhas de desenvolvimento e considera a subjetividade dos pesquisadores e sujeitos estudados como parte da investigação; assim, reflexões, observações, sentimentos e relatos dos pesquisadores tornam-se dados, sendo parte da interpretação, priorizando a profundidade dos mesmos, sendo a coleta de dados feita através de protocolos de avaliação rápida e entrevistas semiestruturadas, além da análise de dados secundários, disponibilizados pela Secretaria Municipal de Saúde de Diamante D’Oeste. Esta análise, portanto, é feita com base em informações e relatórios disponibilizados pelo município e pela Regional de Saúde do município de Toledo. Nestes relatórios, foram verificadas as condições de infraestrutura do município, tais como abastecimento de água na rede pública, esgotamento sanitário, destinação do resíduo sólido, visando ao saneamento básico, e também os dados epidemiológicos do município, com a identificação das principais enfermidades que ocorrem, sejam endêmicas ou epidêmicas.

Portanto, a análise desses dados foi realizada quanti-qualitativamente, de acordo com as respostas dos sujeitos e documentos analisados. Os dados foram digitalizados em um banco geral de dados em um Sistema de Informações Geográficas (SIG), com o auxílio do programa ArcGIS explorer on line ${ }^{\circledR}$, para o planejamento e elaboração dos diversos mapas, dando uma ampla visualização da situação. 


\section{Resultados e Discussões}

A coleta de dados do projeto de mapeamento e análise da saúde ambiental dos grupos sociais em Diamante D'Oeste (PR), integrante do projeto geral de mapeamento social e levantamento socioambiental do referido, foi desenvolvido no período de agosto a setembro de 2012. Foi possível traçar, então, um perfil dos grupos sociais distribuídos no município, como também o tamanho de sua representatividade em porcentagem (Figura 1).

Figura 1 - Universo dos sujeitos entrevistados nas comunidades do município de Diamante D’Oeste - PR (ago./set., 2012)

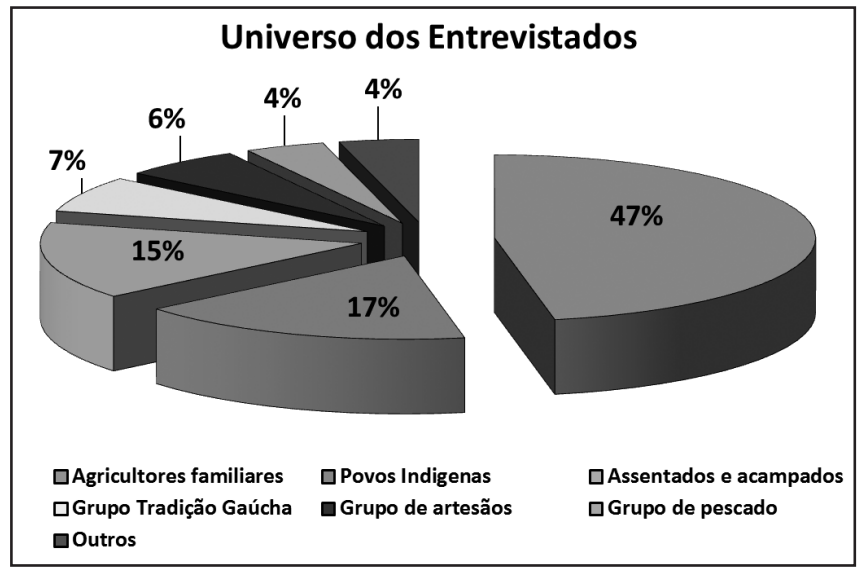

Fonte: Dados da pesquisa.

A partir da visita ao município, foi possível mapear dezesseis comunidades de agricultores familiares, nove clubes de mães, duas aldeias indígenas, incluindo dois grupos, um de artesãos e outro de caça e pesca, além de um assentamento sem-terra, totalizando dezenove comunidades e sete grupos sociais.

É importante ressaltar que o presente trabalho enfoca os resultados obtidos provindos do grupo de maior representatividade, sendo ele o grupo de "Agricultores Familiares", distribuídos em comunidades interioranas. Foi possível demarcar tais comunidades com o auxílio do Global Positiong System (GPS) ${ }^{\circledR}$, marcando suas coordenadas, localizando, assim, o município de Diamante D’Oeste, demonstrando sua inserção no território da Bacia Hidrográfica do Paraná III e a localização das comunidades no município para discussão dos dados encontrados. 
Figura 2 - Mapa com as comunidades demarcadas no município de Diamante D'Oeste - PR (ago./set., 2012)

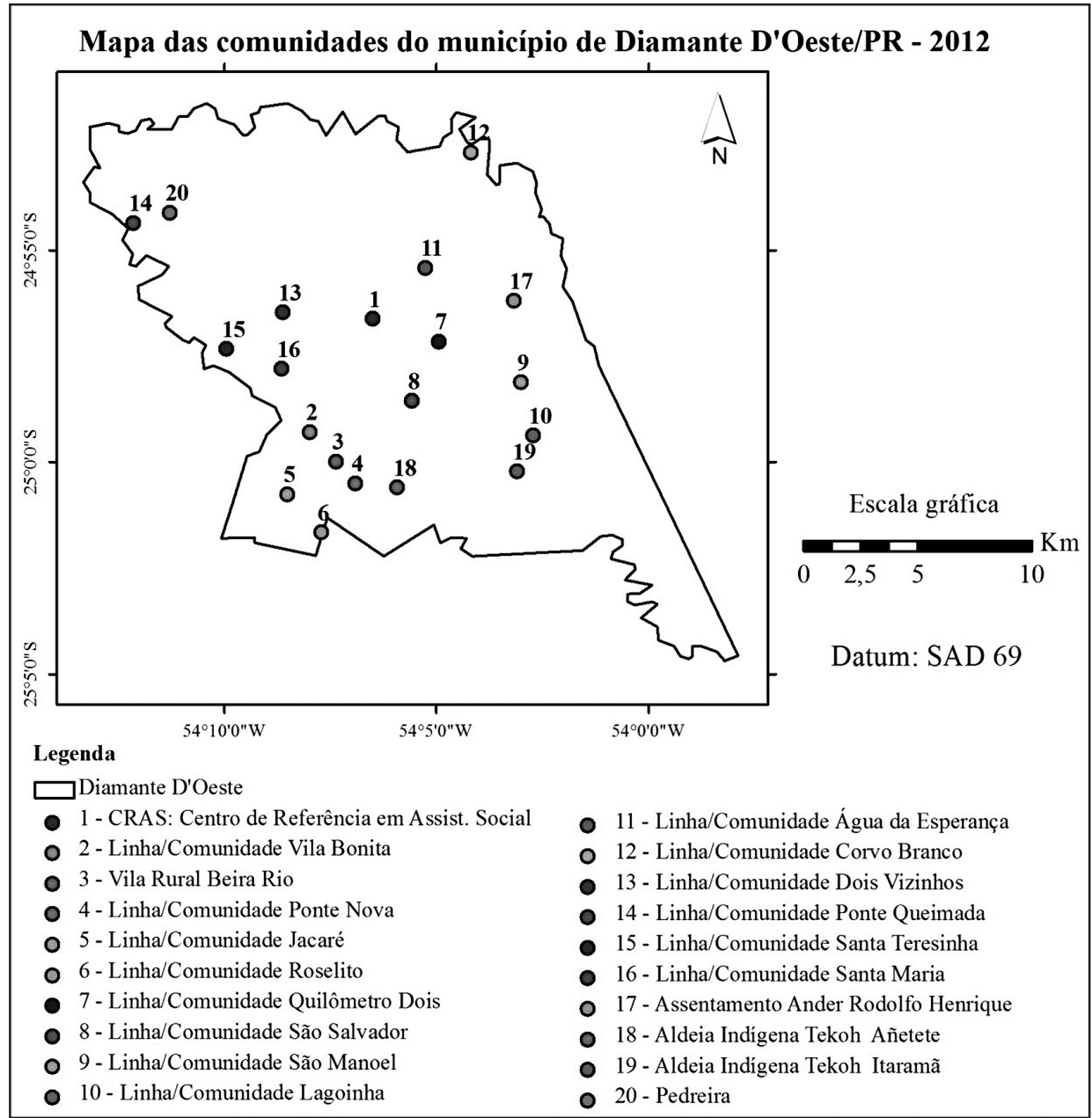

Fonte: Dados da pesquisa.

Analisando as necessidades e agravos à saúde e ao meio ambiente

O primeiro questionamento feito às comunidades seria quem ou qual lugar as pessoas procuravam, quando possuíam algum agravo ou qualquer problema de saúde. Conforme Figura 3, observou-se que, em muitas comunidades, o posto de saúde do município é procurado em quase todos os casos. 
Figura 3 - Número de entrevistados, de acordo com a procura por auxílio à saúde no município de Diamante D’Oeste - PR (ago./set., 2012)

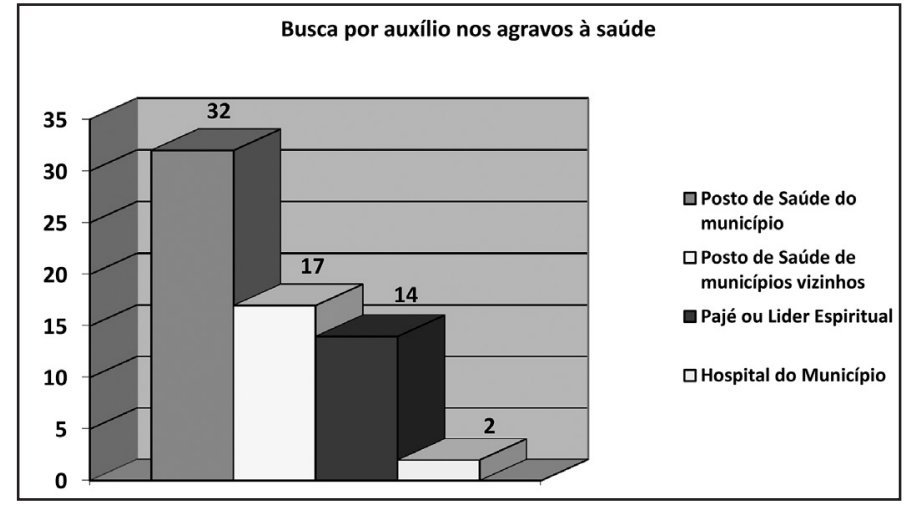

Fonte: Dados da pesquisa.

Um aspecto relatado foi a dificuldade de acesso e de deslocamento da comunidade até o município onde o posto se localiza, como diz A22 “[...] o posto de saúde fica $3 \mathrm{~km}$ daqui, e é difícil ir até lá por causa da estrada e falta de transporte", e também a demora por uma consulta, devido aos poucos atendimentos disponíveis, porém o atendimento é feito com qualidade para a maioria dos indivíduos. Outro aspecto relatado foi que algumas comunidades se localizam longe do centro de saúde do município, obrigando-os, muitas vezes, a procurar auxílio em municípios vizinhos, que também atendem tais comunidades distantes, principalmente a comunidade do Corvo Branco, cuja localização fica na divisa dos municípios Diamante D’Oeste e São José das Palmeiras.

Outros indivíduos procuram o hospital da cidade, quando os casos são mais graves e não é possível o atendimento no posto de saúde da cidade, como diz A20:

[...] como a cidade fica muito longe, preferimos ir até São José, pois lá o atendimento é mais fácil.

Dados atualizados da presente pesquisa revelam que, em uma das duas aldeias que o município possui, setenta e três famílias ali instaladas há aproximadamente sete anos, pertencentes à etnia de índios Avá Guarani, que viviam na triangulação (Marco das Três Fronteiras) em São Miguel do Oeste, devido à construção da Usina de Itaipu, foram distribuídas nas terras do município. Dentro da aldeia, existe uma escola municipal de ensino fundamental, uma unidade básica de saúde, e suas atividades produtivas visam à agricultura e ao artesanato para o comércio.

A aldeia Itamarã é a segunda aldeia do município, possuindo um número menor de famílias, com cerca de quarenta e uma. Também, na aldeia, possuem escola municipal de ensino fundamental, e as principais atividades são o plantio de milho, mandioca, batata, erva medicinal e outras monoculturas. Os principais problemas relatados foram a falta de alimentos, perda da cultura, doenças manifestadas na população indígena, secas e períodos de improdutividade de solo.

Foi observada nas aldeias indígenas uma unanimidade dos entrevistados, quando 
relataram que a procura por cura e saúde primeiramente se dá por meio do pajé ou líder espiritual; assim, existe uma "pré-consulta", para, depois, procurar auxílio médico, o que demonstra a força cultural e a tradição dos povos indígenas. O pajé é uma pessoa de extrema importância dentro das tribos, com muitos conhecimentos, incluindo a história da tribo, sendo que ele é o indígena mais experiente, responsável por passar adiante a cultura, a história e as tradições. O pajé também possui a função de líder espiritual da tribo. Os indígenas acreditam que o pajé possui a capacidade de entrar em contato direto com os deuses. Em algumas tribos, os indígenas acreditam que o pajé tem poderes capazes de fazer chover e melhorar a capacidade dos índios durante a caça e a pesca. Durante a pajelança, o pajé entra em contato com os espíritos de pessoas ou animais mortos, com o objetivo de promover curas, resolver problemas pessoais dos índios ou da tribo, utilizando ervas ou outras plantas. Algumas falas dos entrevistados reforçam tal crença:

A1 - Pajé sempre antes de procurar um médico.

A4 - Médico que vem na aldeia, mas antes o pajé com rezas.

Também foi relatado que, dentro da aldeia Añetete, há um posto de saúde financiado pelo governo federal, que atende a todos os indígenas das duas aldeias. Isto foi uma reivindicação das aldeias, já que o deslocamento até a área urbana seria muito difícil.

No segundo momento, perguntou-se quais seriam os principais agravos ou doenças que os moradores das comunidades, sejam crianças ou adultos, apresentavam com maior frequência. Conforme Figura 4, as principais doenças mencionadas foram gripes ou problemas respiratórios típicos, como dores de garganta, tosse ou espirros, diarréias, dores de cabeça, dores no corpo, febres e náuseas. Ressaltamos que tais doenças eram observadas tanto em adultos como em crianças, em diferentes períodos do ano. Estes principais agravos são ditos como sintomas rotineiros. Nota-se que, pela grande prevalência de crianças e idosos nas comunidades, o índice de problemas respiratórios foi maior, já que tal faixa etária está mais propícia a estes problemas.

De acordo com o Caderno de Saúde do Município (BRASIL, 2012), verifica-se que os casos de problemas respiratórios atingem um total de $20 \%$ da população em geral, só perdendo para neoplasias (tumores), que chegam a atingir $15 \%$ da população em geral. Também foi observado um grande número de casos de diarréias e febres entéricas relacionadas com a distribuição de água, e que são provocadas pela falta de saneamento básico nas comunidades, e dados do Caderno de Saúde indicam ainda um total de $8 \%$ de doenças relacionadas com o aparelho digestivo. Outro importante agravo citado, que tem relação com a veiculação hídrica, foram as verminoses, que afetam cerca de $5 \%$ da população e, de acordo com os entrevistados, geralmente estão associadas à falta de tratamento da água e à destinação inadequada dos dejetos, o que é validado por indivíduos do Caderno de Saúde do Município, mostrando que cerca de $82 \%$ da população possui fossa rudimentar. Algumas doenças de menor prevalência também foram citadas, como as do sistema cardíaco, que atinge a maior parte dos idosos, além de problemas de pressão e doenças sanguíneas.

De modo geral, os estudos sobre as condições de saúde da população do campo associam o estado nutricional com a posse da terra, os processos de trabalho e a saú- 
de (incluindo o uso de agrotóxicos). A morbimortalidade referida tem relação com os serviços de saúde. A literatura aponta para um maior déficit nutricional, à medida que diminui a posse da terra, além de evidenciar um perfil de saúde mais precário da população rural se comparada à urbana. No campo, ainda existem importantes limitações de acesso e de qualidade dos serviços de saúde, bem como uma situação deficiente de saneamento ambiental.

O processo de "modernização conservadora" da agricultura no Brasil ainda tem agravado mais esse quadro, uma vez que criou novos riscos socioambientais para a saúde dessa população. Toda essa discussão sugere que, no Brasil, existe um quadro de franco desfavorecimento da população rural em relação à urbana no que se refere às condições de vida, trabalho e saúde. Não se compartilha aqui da visão de que o "rural" seja uma esfera atrasada, arcaica, passiva e superada, mas, sim, de que é necessário o estabelecimento de políticas públicas justas e inadiáveis, que resgatem essa imensa dívida social, cultural, ambiental e sanitária com as populações do campo (BRASIL, 2012).

\section{Figura 4 - Principais doenças relacionadas nas comunidades do município de Diamante D’Oeste - PR (ago./set., 2012)}

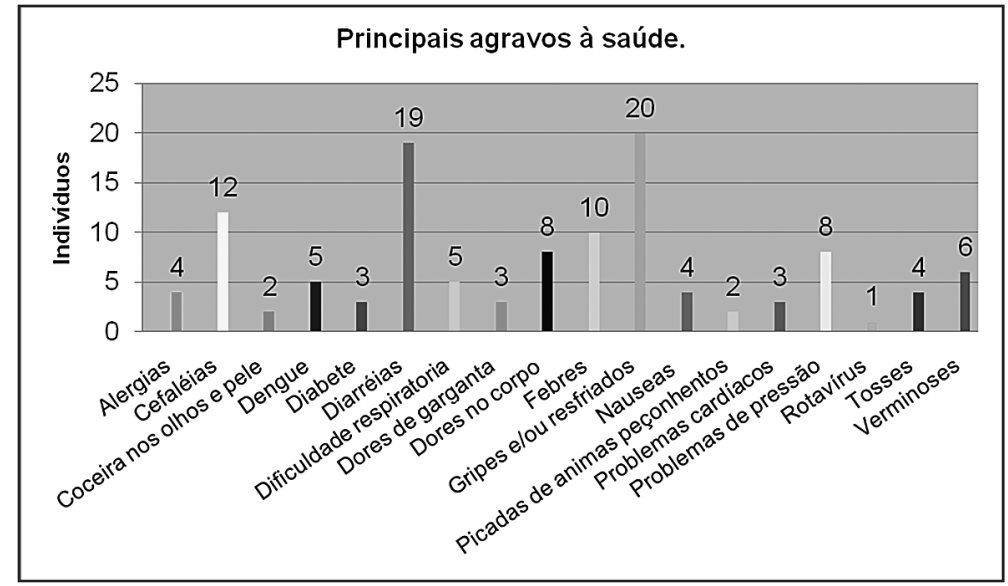

Fonte: Dados da pesquisa.

Ressaltamos que estes principais agravos mencionados na questão anterior estão intimamente interligados por questões de saneamento básico, pois a distribuição de água, para consumo com qualidade, é requisito mínimo para a prevenção de doenças como diarréias ou verminoses. Com relação à distribuição de água no município de Diamante, verificou-se na grande maioria das comunidades rurais visitadas, que a água provém de poços, que não são tratados, ou de nascentes nas propriedades. Apenas na área urbana é feita distribuição de água tratada. Esta questão evidencia a falta de infraestrutura na área rural do município, precária, em algumas situações, também devido à falta de recursos e verbas para tal projeto. Apesar desta falta de saneamento, a situação geral está mudando, sendo que mais da metade dos moradores, os quais não tinham tratamento de água em 1991, já foi atendida. 
Observa-se também a questão do tipo de instalação sanitária, já que foram mencionados pelos moradores alguns casos de verminoses, além também da dificuldade na destinação dos dejetos. Ainda, a principal forma de instalação sanitária continua sendo a fossa rudimentar, sendo que, para a instalação sanitária adequada, seria preciso uma melhor infraestrutura, necessitando de mais recursos financeiros.

Questionou-se junto aos entrevistados quais seriam as principais formas de tratamento utilizadas pelos moradores das comunidades. Notou-se, conforme a Figura 5, que muitos usam remédios caseiros, antes da procura por produtos farmacêuticos, geralmente plantas medicinais para preparar chás utilizados em problemas digestivos ou respiratórios frequentes, como gripes ou diarréias. Estas plantas medicinais são retiradas da própria propriedade ou até mesmo de hortas cultivadas. A fala de um entrevistado exemplifica tal achado: "Folha de laranja, malva" (A17). Estes chás foram citados como um grande remédio caseiro, ajudando antes ou depois do tratamento clínico. Isto é observado nas comunidades rurais, onde existe a tradição caseira. Algumas comunidades participam de cursos de fitoterapia, onde aprendem a utilizar as principais plantas medicinais, e consideram o resultado muito mais eficaz, em comparação aos produtos farmacêuticos.

Figura 5 - Principais formas de tratamentos nas comunidades do município de Diamante D’Oeste - PR (ago./set., 2012)

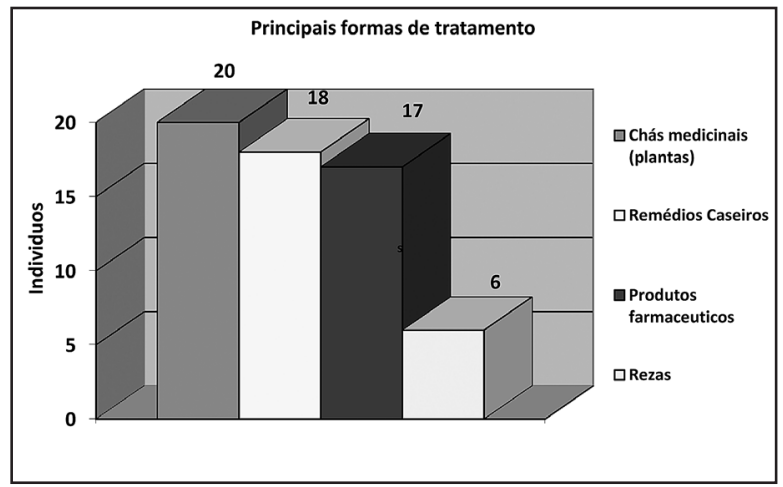

Fonte: Dados da pesquisa.

Entre as possíveis causas para os agravos à saúde, obtiveram-se os resultados demonstrados na Figura 6, inserida na próxima página. 
Figura 6 - Principais causas para doenças nas comunidades do município de Diamante D'Oeste - PR (ago./set., 2012)

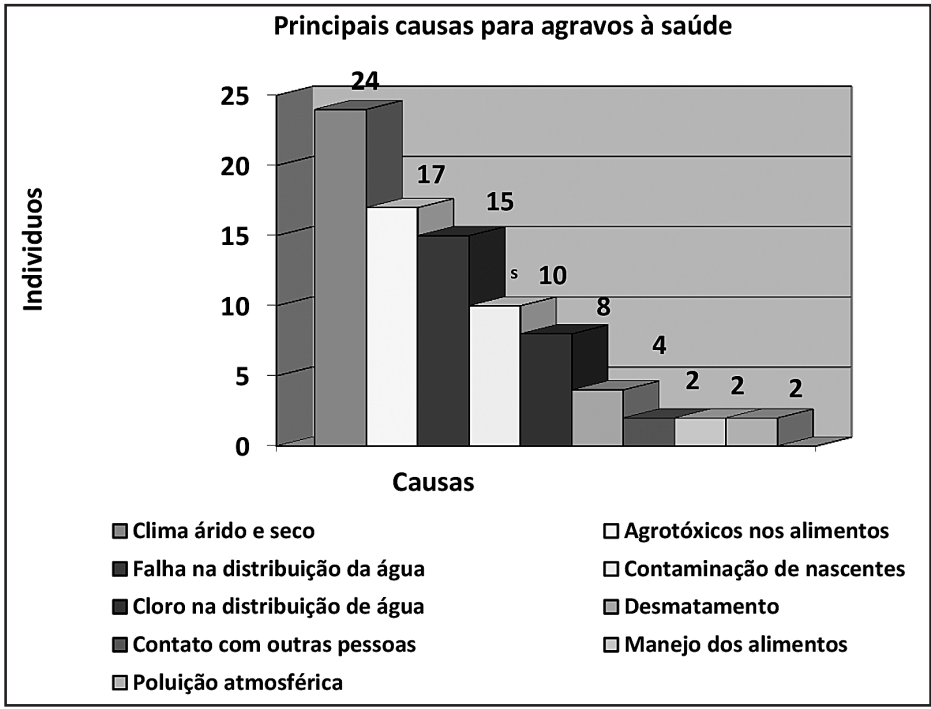

Fonte: Dados da pesquisa.

A principal causa de doenças citada foi o clima seco ou árido, ocasionado pela falta de chuva e baixa umidade do ar. Muitas pessoas que pensam estar sempre com resfriado apresentam apenas obstrução nasal frequente, com espirros repetidos e coceira no nariz, olhos, garganta ou ouvidos. Isso, com o clima seco, tende a se agravar, uma vez que o oxigênio entra mais seco pelo nariz, levando à inflamação e produção excessiva de secreção. No nariz, o ar deve ser umidificado e filtrado. Com a umidade muito baixa, o ar chega ainda muito seco nos pulmões, o que também dificulta a situação de crianças e idosos, que possuem uma maior prevalência para estas doenças. Esta causa é exemplificada nas falas dos entrevistados nas comunidades:

A7 - Tem relação, por exemplo, a falta de chuva, ar mais seco, consequentemente, problemas respiratórios.

A5 - Ambiente muito seco, sem chuva.

A10 - Sim, falta de chuva, ar seco.

A14 - Por causa da natureza, que está secando, ficando muito quente.

A9 - Sim, principalmente problemas climáticos.

A poluição atmosférica também foi mencionada nas entrevistas; diariamente, cada pessoa inala cerca de 10 a 20 mil litros de ar contendo inúmeros tipos de poluentes sob a forma de gases e partículas respiráveis, como fibras e até microorganismos vivos. Alguns desses poluentes têm sua origem em específicos processos químico-industriais, e suas emissões, portanto, restritas a determinadas áreas mais industrializadas, enquanto outros são lançados e disseminados amplamente na atmosfera, responsável pelo trans- 
porte e veiculação desses poluentes para os demais compartimentos ambientais (FUNASA, 2002).

Durante a coleta dos dados, observamos que, em muitas comunidades, o resíduo sólido é incinerado, pois relatam que a coleta de resíduo sólido é feita uma vez por mês pela prefeitura, e que a coleta não é seletiva, sendo que os resíduos sólidos não têm a destinação correta. De acordo com dados do Caderno de Saúde do Município (BRASIL, 2010), cerca de $40 \%$ dos moradores queimam seu resíduo sólido na propriedade, assim como destaca um morador da comunidade:

A19 - [...] na mata da Itaipu, jogava resíduo sólido na propriedade, além do resíduo sólido queimado.

Outra causa citada pelos entrevistados foi a utilização de agrotóxicos nas lavouras, e, consequentemente, a contaminação dos alimentos ingeridos. Muitos moradores das comunidades próximas de grandes propriedades produtoras se queixaram dos efeitos que os agrotóxicos utilizados deixavam na água e nos alimentos ingeridos, até mesmo do forte cheiro produzido.

Os avanços tecnológicos obtidos, nas últimas décadas, principalmente nas atividades industriais e agrícolas, têm contribuído para a introdução de novos agentes químicos nas águas e solos, resultando em graves impactos sobre o ecossistema, especialmente sobre os organismos vivos. Esses efeitos podem ser observados, inicialmente, no topo da cadeia alimentar, pelas mudanças no perfil populacional das espécies predadoras. Uma das classificações dos poluentes das águas e solos está baseada em suas respectivas origens e utilizações. Podemos considerar, portanto, quatro principais fontes desses poluentes químicos ambientais: industrial, agrícola, doméstica e urbana e de ocorrência natural (FUNASA, 2002).

Muitos moradores evidenciaram este fato através de suas falas:

A17 - Agrotóxico, só de passar na estrada já fico ruim.

A16 - Não come nada, nenhuma folha de alface que não tenha agrotóxico, veneno no rio pode correr na plantação.

De acordo com FUNASA (2002), a produção, utilização e disposição dos produtos químicos das indústrias podem gerar a contaminação das águas e do solo. Um dos maiores problemas de diversas indústrias é quanto à disposição dos seus resíduos químicos, que vão desde os produtos detergentes utilizados em simples lavanderias até aqueles usados em processos industriais de transformação química mais complexa. $A$ utilização de substâncias químicas na agricultura também pode resultar em contaminação das águas e dos solos, incluindo o uso de fertilizantes e pesticidas. Alguns pesticidas, por exemplo, são aplicados diretamente no solo, para o controle de insetos e pragas, podendo persistir por alguns anos, além de interferir na fauna e flora presentes. Quanto ao tempo de persistência dos pesticidas no solo, eles podem ser classificados de acordo com o tempo necessário para que $75 \%$ a $100 \%$ dos seus resíduos não sejam mais encontrados, a partir do sítio ou local de aplicação: até 12 semanas após a aplicação do produto, moderadamente persistentes (de 1 até 18 meses), e altamente persistentes (de dois até cinco anos). 
Entre os pesticidas altamente persistentes no solo, podemos citar os organoclorados (DDT, DDD, Aldrin, Dieldrin, Clordane, Lindano) e o herbicida Paraquat. Os herbicidas do grupo das feniluréias e das dinitroanilinas são considerados moderadamente persistentes, com efeitos adversos insignificantes para o ambiente devido ao seu baixo grau de toxicidade. Os inseticidas organofosforados e carbamatos são, relativamente, não persistentes no meio ambiente, já que o processo de interação com alguns componentes do solo e sua rápida degradação bioquímica resultam em uma mínima contaminação do solo e das águas. Entretanto, o aldicarb constitui uma exceção entre os pesticidas carbamatos não persistentes, em razão de sua alta toxicidade e possibilidade de contaminação dos lençóis freáticos (FUNASA, 2002).

Outra causa também amplamente citada foi em relação aos recursos hídricos, seja pela distribuição, tratamento ou contaminação de nascente e rios. Estas três causas estão dentre os principais problemas detectados nesta pesquisa.

A vigilância e o controle da qualidade da água de consumo humano têm como finalidade o mapeamento de áreas de risco em determinado território, utilizando a vigilância da qualidade da água consumida pela população, quer seja a distribuída por sistemas de abastecimento de água e/ou soluções alternativas (com materiais coletados diretamente em mananciais superficiais, poços ou caminhões pipa), para avaliação das suas características de potabilidade, ou seja, da qualidade e quantidade consumida, com vista a assegurar a qualidade da água e evitar o adoecimento das pessoas, ocasionado pela presença de patógenos ou outros poluentes presentes nas coleções hídricas (FUNASA, 2002). Nas entrevistas, destacamos algumas frases nas quais se evidencia tal situação:

A38 - A água chega vir branca de tanto cloro.

A36 - Tudo é jogado no rio por aqui.

A15 - Falta tratamento da água, de vez em quanto a água chega ficar marrom de tanta sujeira.

Também se destaca a contaminação dos alimentos seja por agrotóxicos ou outros microorganismos que estariam presentes nos alimentos: A7: "Preparo incorreto do alimento, carne, peixe contaminado".

As doenças causadas por vetores também foram citadas nas comunidades, em número menor, mas evidentes e de grande importância para a vigilância em saúde como reflexo da falta de medidas preventivas. A12: "Sim, animais peçonhentos, doenças causadas por insetos, mosquitos, etc.".

Em relação aos fatores de risco biológico para a saúde humana, já existe uma longa e histórica atuação do setor saúde, tanto nos aspectos de vigilância, quanto em relação ao controle, podendo-se listar as ações do setor quanto às chamadas doenças transmitidas por vetores, hospedeiros e reservatórios (malária, febre amarela, dengue, esquistossomose, leptospirose, raiva, etc.) (FUNASA, 2002).

Por fim, indagamos a questão da preservação do meio ambiente e prevenção de doenças, obtendo os resultados, a serem apresentados na Figura 7. Dentre os entrevistados, $25 \%$ têm como ação de preservação a não utilização de agrotóxicos nas plantações, e outros $25 \%$, a preservação de nascentes e rios, já que estas pessoas, geralmente agricultores familiares, dependem diretamente do solo e da água para suas produções, 
como fica evidenciado nas falas a seguir:

A2 - [...] pois é o meio ambiente que nos dá tudo que precisamos.

A17 - Se a vertente do senhor secar, a nossa aqui já era.

A21 - Importante, pois vivemos no ambiente, e, se ele não estiver bom, podemos sofrer com isso.

A7 - Lavar bem os alimento, usar pouco veneno e agrotóxicos, não jogar o resíduo sólido no rio.

Essas ações vão desde a preservação da mata ciliar (18\%) até a preservação da fauna e da flora (22\%). Isso foi observado em todas as comunidades que estão à margem do falso rio São Francisco e que se utilizam desse rio para suas atividades. Muitos agricultores destacaram como exemplo as áreas de preservação permanente, além dos limites impostos para a preservação da mata ciliar, como se observa nas falas dos entrevistados:

A22 - Cuidar da mata nascente, mata ciliar.

A6 - Não destruir locais próximos aos rios, preservar mata ciliar.

A13 - [...] porque não tem mais a natureza para proteger porque já acontece o desmatamento e não tem mais proteção...

A13 - Não podemos derrubar arvores, limpar ao redor dos rios, cuida melhor porque não tem mais mata.

A24 - Preservar mata ciliar, rios, cuidados na alimentação, sem agrotóxicos.

O conceito de Áreas de Preservação Permanente (APP), as quais foram instituídas no Código Florestal Brasileiro - Lei no 4.771 de 15/09/1965 (BRASIL, 1965), emerge do reconhecimento da importância da manutenção da vegetação de determinadas áreas, as quais ocupam porções particulares de uma propriedade, não apenas para os legítimos proprietários dessas áreas, mas, em cadeia, também para os demais proprietários de outras áreas dessa mesma comunidade, de comunidades vizinhas e, finalmente, para o bem de todos os membros da sociedade.

De acordo com o Código Florestal Brasileiro (BRASIL, 1965), as Áreas de Preservação Permanente (APP) são

[...] cobertas ou não por vegetação nativa, com a função ambiental de preservar os recursos hídricos, a paisagem, a estabilidade geológica, a biodiversidade, o fluxo gênico de fauna e flora, proteger o solo e assegurar o bem-estar das populações humanas.

Distinguem-se das áreas de "Reserva Legal", também definidas no mesmo Código, por não serem objeto de exploração de nenhuma natureza, como pode ocorrer no caso da Reserva Legal, a partir de um planejamento de exploração sustentável. Exemplos de APP são as áreas marginais dos corpos d'água (rios, córregos, lagos, reservatórios) e nascentes; áreas de topo de morros e montanhas, áreas em encostas acentuadas, restingas e mangues, entre outras. 
Figura 7 - Principais ações de preservação do meio ambiente e prevenção de doenças nas comunidades do município de Diamante D'Oeste - PR (ago./set., 2012)

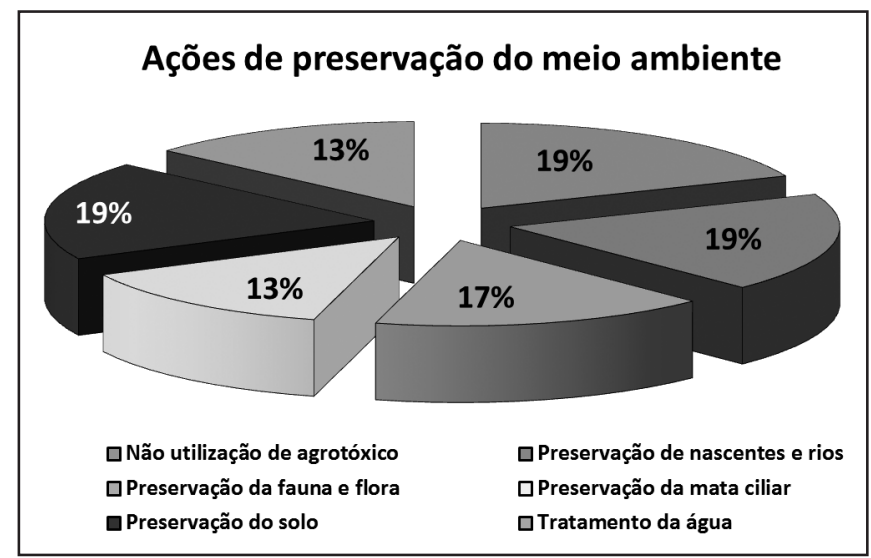

Fonte: Dados da pesquisa.

Morin (1987) aponta que o ser humano é $100 \%$ natureza e $100 \%$ cultura. Esta formulação é de suma importância para a compreensão da relação da saúde com o contexto e as circunstâncias da vida humana. Dentre as várias ações citadas pelos entrevistados, podemos perceber que preservação e conscientização são as principais formas de controlar e diminuir os impactos ambientais. As falas a seguir evidenciam tal apreço pela natureza.

A16 - Tem e muito, porque, se você estiver na cidade, não tem árvore; se você estiver no sitio, a água é cristalina, e o ar é puro, importante preservar.

A23 - Importante preservar, pois o peixe morre pela boca.

A38 - Derrubar árvore não pode, só olha.

Nas diversas visitas às comunidades, percebemos que os moradores têm um grande apreço pelo meio ambiente, muitos reconhecem a importância da preservação, além de realizarem ações efetivas de preservação do meio ambiente. Esta concepção da natureza anda junto com a cultura desses grupos, quando buscamos a sustentabilidade socioambiental dos ambientes e das sociedades.

\section{Considerações Finais}

A perda de qualidade e o esgotamento de elementos da natureza essenciais à vida, como a água, o solo, o ar e a biodiversidade, tornam os problemas de saúde muito mais incertos e preocupantes. O crescimento rápido e pouco planejado dos centros urbanos, aliado aos avanços tecnológicos e às mudanças estruturais globais, resultou em novas formas de produção e ocupação territorial, consolidando mudanças nos hábitos da população e criando novos padrões de consumo, modificando, assim, sem dúvida, a qualidade de vida. 
Dentre os principais agravos à saúde detectados nesta pesquisa, destacam-se aqueles que envolvem principalmente o saneamento básico, a distribuição e tratamento de água, a destinação do esgoto e dos resíduos sólidos, ou até mesmo as mudanças climáticas, influenciando direta ou indiretamente na saúde dos indivíduos pesquisados. Percebeu-se que a preservação do meio ambiente e de todos os seus recursos naturais é fundamental para a continuação da existência humana, e que tais recursos possibilitam aos seres humanos uma qualidade de vida adequada. Em muitas comunidades, foi observado grande apreço pela natureza, ou seja, pelas matas, rios, nascentes, animais, até mesmo pelo solo, principal recurso para os agricultores familiares e todos os que retiram seu sustento da terra.

A presente pesquisa possibilitou também, junto às comunidades estudadas, a abordagem de alguns assuntos ambientais e da educação em saúde, até mesmo pelo pouco tempo de coleta dos dados referentes à saúde ambiental, destacando formas de prevenção de doenças relacionadas ao meio ambiente e promoção da saúde.

\section{Referências}

AMARAL, A. Q.; CARNIATTO, I. Concepções sobre projetos de educação ambiental na formação continuada de professores. Revista electrónica de investigación em educación em ciências. v. 6, n. 1, p. 113-123, 2011. Disponível em: <http://www.scielo.org.ar/pdf/ reiec/v6n1/v6n1a10.pdf >. Acesso em: 24 abr. 2012.

BARBIER, R. A pesquisa-ação. Brasília: Plano, 2002.

BRASIL. Lei no 4.771, de 15 de setembro de 1965. Institui o novo Código Florestal Brasileiro. Diário Oficial da República Federativa do Brasil. Brasília, 1965.

BRASIL. Ministério da Saúde. Caderno de Informação de Saúde município Diamante D’Oeste - Pr. Brasília: Secretaria Executiva, 2010. Disponível em: <ftp://ftp.datasus.gov. br/caderno/geral/pr/PR_Diamante_DOeste_Geral.xls>. Acesso em: 10 out. 2012.

BRASIL. Ministério da Saúde. Sistema nacional de vigilância ambiental em saúde. Brasília, 2003.

BUSS, P. M. Promoção da Saúde e qualidade de vida. Ciências e saúde coletiva, Rio de Janeiro, v. 5, n. 1, p. 163-177, 2000. Disponível em: <http://www.scielo.br/scielo.php? script=sci_arttext\&pid=S1413-81232000000100014>. Acesso em: 4 abr. 2012.

CÂMARA, V. M. Textos de epidemiologia para vigilância ambiental em saúde. Brasília: Ministério da Saúde, 2002.

CARNIATTO, I. A Formação do Sujeito Professor. Cascavel: Edunioeste, 2002.

. Subsídios para um Processo de Gestão de Recursos Hídricos e Educação Ambiental nas Sub-Bacias Xaxim e Santa Rosa, Bacia Hidrográfica Paraná III. Tese (Doutorado) - Engenharia Florestal, Universidade Federal do Paraná, Curitiba, 2007.

CASTRO, A. A. Manual de saneamento e proteção ambiental para os municípios. Belo Horizonte: UFMG, 1995.

CHIZZOTTI, A. Pesquisa em Ciências Humanas e Sociais. São Paulo: Cortez, 1991. 
COSTA, E. M. A.; CARBONE, M. H. Saúde da família: uma abordagem interdisciplinar. Rio de Janeiro: Rubio, 2004.

DOMINGUEZ, B. N. R. O programa de saúde da família: como fazer obra de saúde pública que mostra uma metodologia prática para implantar e gerenciar PSF em seu município. Brasil: CGE, 1998.

FLICK, U. Uma introdução à pesquisa qualitativa. Porto Alegre: Bookman, 2004.

FUNASA. Fundação Nacional de Saúde. Textos de epidemiologia para vigilância ambiental em saúde. Brasília: Ministério da Saúde, 2002.

GIL, A. C. Como Elaborar Projetos de Pesquisa. 4. ed. São Paulo: Atlas, 2002.

GIODA, A.; NETO, F. R. A. Considerações sobre estudo de ambientes industriais e não industriais no Brasil: uma abordagem comparativa. Caderno de Saúde Pública, Rio de Janeiro, v. 19, n. 5, p. 1389-1397, 2003.

HELLER, I. Saneamento e saúde. Brasília: OPAS/OMS, 1997.

IPARDES. Instituto Paranaense de Desenvolvimento Econômico e Social. Caderno Estatístico Município de Diamante d'Oeste, Curitiba, 2011.

LAZZAROTTO, E. M. et al. Educação Ambiental, Saúde e Sociedade: gestão comunitária. Cascavel: Coluna do Saber, 2007.

LUDKE, M.; ANDRÉ, M. Pesquisa em educação: abordagens qualitativas. São Paulo: EPU, 1986.

MINAYO, M. C. de S.; MIRANDAN, A. C. de. (Orgs.). Saúde e Ambiente Sustentável: estreitando nós. Rio de Janeiro: Fundação Oswaldo Cruz, 2002.

MORIN, E. A Natureza da Natureza. Portugal: Europa América, 1987.

SILVA, R. A. Do invisível ao visível: o mapeamento dos grupos sociais do estado de Mato Grosso. Tese (Doutorado em Ecologia e Recursos Naturais) - Universidade Federal de São Carlos, São Carlos, 2011.

TAMBELINNI, A. M.; CÂMARA, V. de A. Temática Saúde e Ambiente no Processo de Desenvolvimento do Campo da Saúde Coletiva: aspectos históricos, conceituais e metodológicos. Ciências e Saúde Coletiva, Rio de Janeiro, v. 3, n. 2, p. 47-59, 2003. 